united by silk sutures and the edges of the wound were brought together, a drainage tube being inserted through a separate incision on the outer side of the joint. A dressing of double cyanide ganze and absorbent wool was applied, and the limb was fixed in plaster of Paris. On May 3rd the stitches were removed, and the plaster sprint was exchanged for a wooden back splint. On the 12th the patient was allowed to sit up; on the 19 th the splint was removed; and on May 24th, when he was discharged from the hospital, i.e., less than five weeks from the time of the accident, he had firm union of the patella and was able to walk. This case is a good illustration of the advantages of the completely open method in dealing with fracture of the patella. Roughly, it may be said that, except in the aged, if there is a separation of more than a finger's width between the fragments some operative method will have to be adopted if a good and firm union between them is to be secured. It then becomes a question whether subcutaneous wiring or an open operation is the best, and, as we said in commenting on the accident to the Prince of Wales at the time of its occurrence, a strong feeling has lately grown up among many surgeons in favour of the completely open operation, the idea being that, if the risks inseparable from any operation have to be run, it is best to do an operation such as the one above described, which shall give full opportunity for removing all blood and other effusion, and of making certain that the bones are actually in contact, and that no fibrous structures are lodged between the broken surfaces. The case just mentioned shows how correct this view is, and what good success may follow such an operation, even although at the time of the accident much risk had been run of septic infection of the wound.

\section{THE MARRIAGE OF THE UNFIT}

Dr. Harry Campbell,' writing on the marriage of the unfit, would very considerably extend the boundaries of that group of diseases which go by the name " hereditary," and would thus increase in no small degree the number of those who, for the benefit of the race, ought to be held unfit for marriage. He shows how largely natural selection is interfered with among civilised communities - on the one hand, by a continual saving of lives which in more natural conditions would succumb, and, on the other, by the abolition of polygamy. Patting polygamy, however, more or less regretfully on one side as a means of rejurenating the race, and taking the institution of marriage as it stands, the question is, Who should marry? or, perhaps, more properly, Who should refrain from marriage?

Into the latter category Dr. Harry Campbell places at once all sufferers from pulmonary consumption, organic heart disease, epilepsy, insanity, diabetes, and chronic Bright's disease, and also from rheumatic fever, if there has been more than one attack, as obviously unfit. To these he adds all those cases of non-accidental disease in which life is saved by the surgeon's skill, cases which in a less artificial condition of existence would be weeded out by natural selection and thus prevented from transmitting to others a like defect. "Think," he says, "of the millions and millions of women suffering from ovarian cyst whom nature has in the past sacrificed with a cruel kindness in order to keep a certain level of ovarian fitness in the race. These are practically all saved now in civilised communities, with the result that the percentage of ovarian cysts is necessarily increasing. It can only be that medical men do not realize the potency of heredity that they sanction the propagation of children by women whose lives have been saved in this manner."

The class of disorders, however, which Dr. Campbell thinks "should bejond almost all others be regarded as a bar to marriage" are functional disorders of the nervous system. The highly sensitive, he says, are not suited for this hard world; its strenuous conditions call for men of iron nerve and stout hearts, and, as regards happiness, the fine animal with little imagination and a good thick akin has the best time of it-in other words is the most " fit."

It is pointed out that the lives of people with weak nerves are often one long drawn out misery, and to the neurotic man the advice is given " Remain single." As a counsel of perfection this may be right enough, and it may perhaps, be true that a world of stolid thickskinned mediocrities offers the greatest happiness for the greatest number. Nevertheless we look with some regret at the idea of a world without neurotics. In one of the most brilliant lectures ever delivered before the Royal College of Physicians, Professor Clifford Allbutt said, "Why, gentlemen, my neurotic patients are almost the best people in this wicked world! Rarely endowed with the capacity, endurance, and profounder imagination of the greatest, they form a large number of those in the second rank who are the salt of the earth." Yet, perhaps, if the happiness of posterity is to be looked upon as our end and aim, even the neurotics had better refrain from marriage, for, great as are their mental aptitudes, their capacity for sinking into the depths of wretchedness is undoubted-and this also is hereditary.

\section{THE WASTE OF WATER.}

No improvement has taken place in the water supply in the East of London, although, as the officials of the water company maintain, a very large amount of water is being daily pumpedinto the district. The question that occurs to everyone is-What becomes of all this flood of water? and the Times answers without hesitation, "It is wasted." The inference is suggested that the company has done its duty when it has pumped into the district an amount of water which, judging by the experience of many other places, ought to be amply sufficient for all purposes. We cannot, however, accept so simple a view of the matter. The duty of a company is to supply the individual householder, not the district at large, and the statements which are current as to the considerable quantity of water now being supplied only go to prove that the arrangements made by the company for its distribution and for the prevention of waste are utterly defective. These are matters over which the consumers have no control, and it is idle to throw on that vague body, "the public," the blame for the waste of water. However careful a householder may be, the sight of a neighbour going unpunished, though his taps are always running, is an 